\title{
Antitumor Effect of a Novel Photodynamic Therapy With Acetylated Glucose-conjugated Chlorin for Gastrointestinal Cancers
}

\author{
HIROSHI ICHIKAWA ${ }^{1}$, HIROTADA NISHIE ${ }^{1}$, SHIGENOBU YANO ${ }^{2,3,4}$, YUKI KOMAI ${ }^{5}$, HIROAKI YAMAGUCHI ${ }^{5}$, \\ AKIHIRO NOMOTO ${ }^{5}$, TAKETO SUZUKI ${ }^{1}$, MAMORU TANAKA ${ }^{1}$, TAKAYA SHIMURA ${ }^{1}$, \\ TSUTOMU MIZOSHITA ${ }^{1}$, EIJI KUBOTA ${ }^{1}$, SATOSHI TANIDA ${ }^{1}$ and HIROMI KATAOKA ${ }^{1}$ \\ ${ }^{1}$ Department of Gastroenterology and Metabolism, \\ Nagoya City University Graduate School of Medical Sciences, Nagoya, Japan; \\ ${ }^{2}$ Graduate School of Materials Science, Nara Institute of Science and Technology, Ikoma, Japan; \\ ${ }^{3}$ Minerva Light Laboratory, L. C. C., Kyoto, Japan; \\ ${ }^{4}$ KYOUSEI Science Center for Life and Nature, Nara Women's University, Nara, Japan; \\ ${ }^{5}$ Department of Applied Chemistry, Graduate School of Engineering, Osaka Prefecture University, Osaka, Japan
}

\begin{abstract}
Background/Aim: We previously synthesized a glucose-conjugated chlorin compound e6 (G-chlorin e6), and reported that it has very strong antitumor effects. The aim of the present study was to synthesize acetylated glucoseconjugated chlorin (AcNOO3HP) and evaluate its antitumor effect and excretion. Materials and Methods: To evaluate the antitumor effect of AcNOO3HP, its $I C_{50}$ was calculated as well as its accumulation in cancer cells was examined by flow cytometry. Confocal microscopy was used to observe the intracellular localization of AcN003HP. The excretion and antitumor effects of AcNOO3HP were also evaluated in vivo. Results: AcN0O3HP showed stronger antitumor effects and accumulation into cancer cells compared to talaporfin sodium, a conventional photosensitizer. AcNOO3HP was localized in the endoplasmic reticulum. In a xenograft tumor mouse model, AcN0O3HP showed longer excretion time from the body than G-chlorin e6, and photodynamic therapy using AcNOO3HP showed very strong antitumor effects. Conclusion: The safety, improved controllability, and robust antitumor effects suggest AcNOO3HP as a good next-generation photosensitizer.
\end{abstract}

Photodynamic therapy (PDT) is a minimally invasive and less systemically toxic treatment for cancer. In this therapy,

Correspondence to: Hirotada Nishie, Department of Gastroenterology and Metabolism, Nagoya City University Graduate School of Medical Sciences, 1 Kawasumi, Mizuhocho, Mizuho-ku, Nagoya 467-8601, Japan. Tel: +81 528515511, e-mail: nishix589998@yahoo.co.jp

Key Words: Acetylated glycose-conjugated chlorin, gastrointestinal cancer, photodynamic therapy. after administration of a photosensitizer (PS) and appropriate wavelength light irradiation, the PS generates cytotoxic reactive oxygen species (ROS) (1). The ROS induce tumor cell death through necrosis or apoptosis (1-6). Although PDT potentially has some adverse effects, such as skin photosensitivity, severe complication rates due to PDT are reported to be extremely low $(7,8)$.

PDT is widely used in the medical field. In Japan, PDT and two PSs, porfimer sodium and talaporfin sodium (TS), have been approved by the health insurance scheme. Porfimer sodium is a first-generation PS and TS is a second-generation PS. PDT using these PSs requires a period of light shielding after administration of PS. Porfimer sodium requires approximately 4 weeks of light shielding. Because TS is rapidly cleared from the body, the light shielding period after light irradiation is relatively short (within 2 weeks) $(9,10)$.

Due to limitations with respect to the light shielding period and the need for stronger antitumor activity, a glucoseconjugated chlorin compound (G-chlorin) was developed as a next-generation PS, based on the Warburg effect, a phenomenon whereby cancer cells consume more glucose than normal cells (11-14). We have previously reported that glucose-conjugated chlorin compound e6 (G-chlorin e6) has a strong antitumor effect and its excretion is very fast compared with conventional PSs (15). In this study, we synthesized AcN003HP (acetylated glucose-conjugated chlorin), which was expected to have a delayed metabolism and excretion from the body and, therefore, better control of the excretion time resulting in improved tumor selectivity and specificity. In addition, the acetyl groups in AcN003HP have an advantage in producing a high antitumor effect $(16,17)$. In the present study, accumulation in cancer cells, cytotoxicity, ROS 


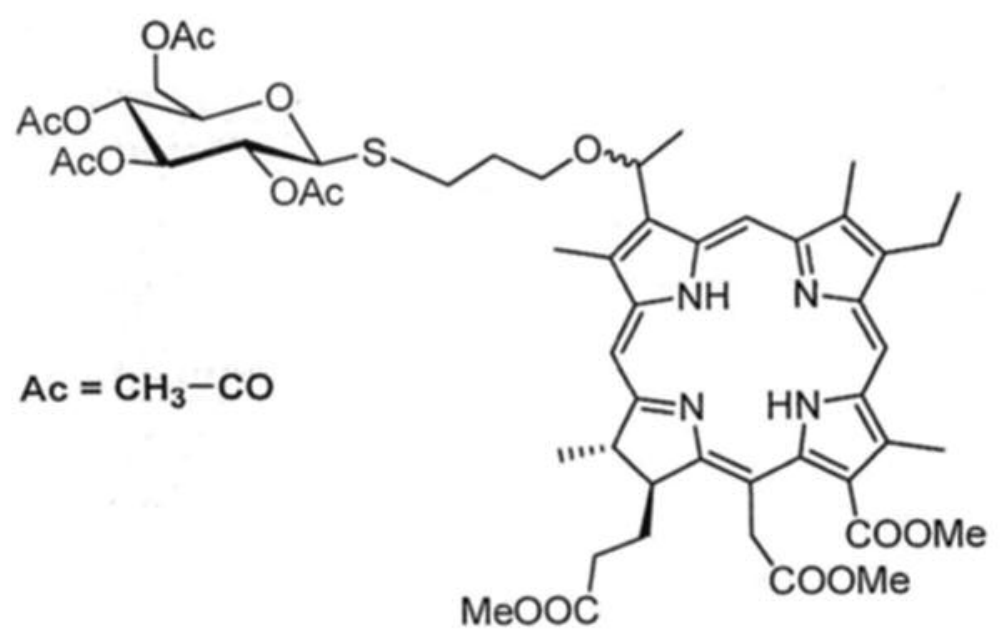

A

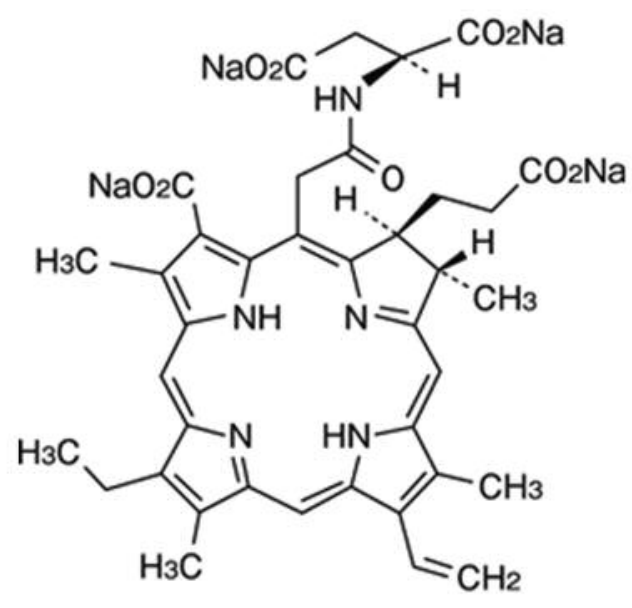

$\mathrm{B}$

Figure 1. Chemical structures of AcN003HP and talaporfin sodium (TS). (A) AcN003HP: 31-(3-(1-thio-b-D-acetylated glucopyranosyl) propoxy) Chlorin e6 trimethyl ester (Acetylated G-chlorin e6) Methyl (7S,8S) -18-ethyl-5- (2-methoxy-2-oxoethyl) -7- (3-methoxy-3-oxopropyl) -2,8,12,17tetramethyl-13-(1-(3-(((2S,3R,4S,5S,6R)-3,4,5-trihydroxy-6-(hydroxymethyl) tetrahydro-2H-pyran-2-yl) thio) propoxy) ethyl)-7H,8H-porphyrin-3carboxylate; (B) TS: mono-1-aspartyl chlorin6 (Laserphyrin $\left.{ }^{\circledR}\right)$.

generation, and antitumor effect of AcN003HP was evaluated both in vivo and in vitro, compared to TS.

\section{Materials and Methods}

Photosensitizers. 31-(3-(1-thio-b-D- acetylated glucopyranosyl) propoxy) Chlorin e6 trimethyl ester (acetylated G-chlorin e6) Methyl (7S ,8S)-18-ethyl-5-(2-methoxy-2-oxoethyl)-7-(3-methoxy-3oxopropyl)-2,8,12,17-tetramethyl-13-(1-(3-(((2S,3R,4S ,5S,6R)-3,4,5trihydroxy-6-(hydroxymethyl) tetrahydro-2H-pyran-2-yl) thio) propoxy) ethyl)-7H,8H-porphyrin-3-carboxylate (acetylated Gchlorin e6) was synthesized and provided by the laboratory of the Osaka Prefecture University, Japan (Figure 1A). TS (mono-l-aspartyl chlorin6, Laserphyrin ${ }^{\circledR}$ ) was purchased from Meiji Seika (Tokyo, Japan) (Figure 1B), and 5-ALA was purchased from Cosmo Bio Co., LTD (Tokyo, Japan).

Cell culture. The following cell lines were used: human esophageal cancer cells OE21 (No.11D028; ECACC) and KYSE30, human gastric cancer MKN45 cell line (No. 0254; Japanese Cancer Research Bank), and human colon cancer HT29 cell line (No. HTB38; ATCC); culturing was conducted as previously reported (15).

Animals and models. Female mice (BALB/c nu/nu) aged 4-6 weeks and weighing 15-20 g were purchased from Japan SLC, Inc. (Hamamatsu-shi, Shizuoka, Japan). The mice were acclimatized for at least 2 weeks in the animal facility before any experimentation occurred. A xenograft tumor model was established by subcutaneously implanting $1 \times 10^{6}$ MKN45 cells in $100 \mu \mathrm{l}$ of culture media under the right flank of experimental mice. The Nagoya City University Center for Experimental Animal Science approved the procedures and experiments, and mice were cared for according to the guidelines of the Nagoya City University for Animal Experiments.

Flow cytometry analysis to assess accumulation of PSs in cancer cells. MKN45 cells were seeded into 6 -well culture plates at $2 \times 10^{5}$ cells/well and incubated at $37^{\circ} \mathrm{C}$ for $48 \mathrm{~h}$. The medium was then replaced with fresh medium containing $5 \mu \mathrm{M}$ TS or AcN003HP and incubated for $4 \mathrm{~h}$ to assess the accumulation of PS in cancer cells. Cells were washed with phosphate-buffered saline (PBS) three times and removed from the culture dish with TrypLE-Express (Invitrogen, Waltham, MA, USA). Cells were analyzed by fluorescence-activated cell sorting (FACSCANTO II, BD Biosciences, San Jose, CA, USA) at excitation and emission wavelengths of 405 and $680 \mathrm{~nm}$, respectively.

Intracellular localization of PS. As previously reported (18), we seeded MKN45 cells into culture plates and added AcN003HP. After appropriate incubation, lysosomes, mitochondria, Golgi, and endoplasmic reticulum were labeled using organelle-specific fluorescent probes and visualized for PS localization intracellularly by confocal microscopy (FV3000 Olympus Co., Ltd, Tokyo, Japan) and imaging software (FV31S-SW, Olympus). Band-pass emission filters of 505-530 nm and $650 \mathrm{~nm}$ were used.

Production of singlet oxygen. To detect singlet oxygen $\left({ }^{1} \mathrm{O}_{2}\right)$ production from PDT with AcN003HP and TS, the Singlet Oxygen Sensor Green (SOSG) reagent was used. Human gastric cancer cells (MKN45) were incubated in culture medium and after $24 \mathrm{~h}$, the medium was replaced with medium containing $1 \mu \mathrm{mol} / 1$ of the PS. After incubation for a further $4 \mathrm{~h}$, cells were washed with PBS three times and then covered with PBS supplemented with $2 \mu \mathrm{M}$ of SOSG reagent and irradiated with light-emitting diode (LED) light 

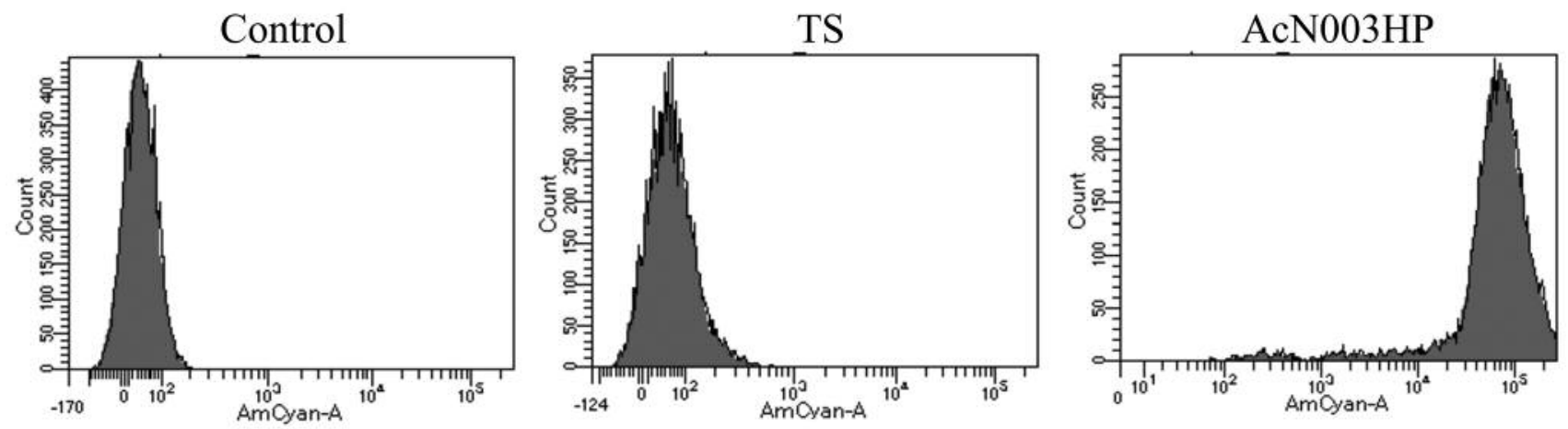

Figure 2. The accumulation of talaporfin sodium (TS) and AcN003HP in gastric cancer cells. MKN45 cells were incubated with TS, AcN003HP, or without photosensitizer as a control, and accumulation of the reagent was evaluated using flow cytometry at 405-nm excitation wavelength and 680-nm emission wavelength. Both AcN003HP and TS contain chlorin as a photosensitizer; the wavelengths of $405 \mathrm{~nm}$ and $680 \mathrm{~nm}$ were nearly the peak excitation and emission wavelengths of chlorin, respectively. The abscissa of the graph indicates cell populations and the ordinate represents the intensity of emission.

(OptoCode Corporation, Tokyo, Japan) at a wavelength of $660 \mathrm{~nm}$ and energy of $16 \mathrm{~J} / \mathrm{cm}^{2}$ (intensity, $36 \mathrm{~mW} / \mathrm{cm}^{2}$ ). The fluorescence of each reagent was measured by a fluorescence microplate reader using a spectrum scan. The wavelength of excitation used for analysis was $504 \mathrm{~nm}$, with the measurement wavelength ranged from 500-600 nm. The obtained data were analyzed with SoftMAX pro software (Molecular Devices, San Jose, CA, USA).

In vitro PDT. Human esophageal, gastric, and colon cancer cells (OE21, KYSE30, MKN45, and HT29) were incubated in culture medium. After $24 \mathrm{~h}$, the medium was replaced with medium supplemented with PS $(0.25-50 \mathrm{nM})$. Cancer cells were then washed and covered with PBS, and irradiated with LED light (OptoCode Corporation) at a wavelength of $660 \mathrm{~nm}$ and energy of $16 \mathrm{~J} / \mathrm{cm}^{2}$ (intensity, $36 \mathrm{~mW} / \mathrm{cm}^{2}$ ).

Cell viability assay. Cell viability was evaluated by the WST-8 cell proliferation assay (Donjindo Laboratories, Kumamoto, Japan). According to methods published previously (15), cancer cells were seeded and incubated with TS or AcN003HP, and then irradiated with LED light, as for in vitro PDT. The cell counting kit-8 solution was added and absorption at $450 \mathrm{~nm}$ was measured using a microplate reader. Cell viability was shown as the percentage of untreated cells, and the $50 \%$ inhibitory concentration $\left(\mathrm{IC}_{50}\right.$ ) for each PS was calculated.

Accumulation of PS in vivo. A total of 30 mice were grouped into 3 groups of 10 mice - Group A, control (no PS); Group B, Gchlorin e6 (1.56 $\mu \mathrm{mol} / \mathrm{kg})$; and Group C, AcN003HP (1.56 $\mu \mathrm{mol} / \mathrm{kg}$ ). MKN45 cells were implanted subcutaneously, and when the tumor had grown to approximately $100 \mathrm{~mm}^{3}$, each PS was administered via the tail vein. After administration, the accumulation of PS was examined using a semiconductor laser with a VLD-M1 spectrometer (M\&M Co., Ltd., Tokyo, Japan). To examine changes over time, we measured fluorescence every $30 \mathrm{~min}$ for $120 \mathrm{~min}$. The spectrometer and its accessory software (BW-Spec V3. 24; B\&W TEK, Inc., Newark, DE, USA) were used to analyze the spectrum waveform and amplitude peak (relative fluorescence intensity) at $505 \mathrm{~nm}$ for autofluorescence,
Table I. Comparison of the 50\% inhibitory concentrations produced by photodynamic therapy with talaporfin sodium and AcNOO3HP in vitro.

\begin{tabular}{|c|c|c|c|c|}
\hline & \multicolumn{2}{|c|}{$\begin{array}{l}\text { Esophageal } \\
\text { cancer }\end{array}$} & \multirow{2}{*}{$\begin{array}{c}\begin{array}{c}\text { Gastric } \\
\text { cancer }\end{array} \\
\text { MKN45 }\end{array}$} & \multirow{2}{*}{ 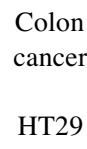 } \\
\hline & OE21 & KYSE & & \\
\hline Talaporfin sodium & 17,400 & 4,290 & 11,400 & 18,500 \\
\hline AcN003HP & 0.48 & 0.56 & 0.88 & 1.48 \\
\hline
\end{tabular}

Esophageal, gastric, and colon cancer cells (OE21, KYSE30, MKN45, and HT29) were incubated with various concentrations of photosensitizer in culture medium for $24 \mathrm{~h}$, irradiated with $16 \mathrm{~J} / \mathrm{cm}^{2}$ of $660-\mathrm{nm}$ lightemitting diode light, and incubated for $24 \mathrm{~h}$. Cell viability was evaluated using the WST-8 assay and expressed as the 50\% inhibitory concentration (nM). Data are means of eight independent experiments.

and at $675 \mathrm{~nm}$ for G-chlorin e6 or AcN003HP. The relative intensities of the PSs measured by the spectrometer were observed to have a linear correlation with PS concentration. To reduce measurement error, the relative fluorescence intensity ratio of the PSs in the target tissue, which were calculated by dividing the relative fluorescence intensity by that of autofluorescence, were evaluated.

In vivo PDT. A total of 21 mice were grouped into 3 groups of 7 mice - Group A, control (no PS); Group B, TS (1.56 $\mu \mathrm{mol} / \mathrm{kg})$; Group C, AcN003HP $(1.56 \mu \mathrm{mol} / \mathrm{kg})$. Gastric cancer MKN45 cells were implanted subcutaneously, and when the tumor had grown to approximately $100 \mathrm{~mm}^{3}$, each PS was administered via the tail vein. Ninety min after administration, the tumors were irradiated with 664 $\mathrm{nm}$ red LASER (OK Fiber Technology) at a dose of $100 \mathrm{~J} / \mathrm{cm}^{2}$ (intensity, $150 \mathrm{~mW} / \mathrm{cm}^{2}$ ). Tumor growth was monitored every 3 days after irradiation. The tumor was measured with vernier calipers and the tumor volume was calculated by the formula, length $\times$ width $\times$ depth/2. Differences between groups were evaluated by Welch's $t$-tests. 


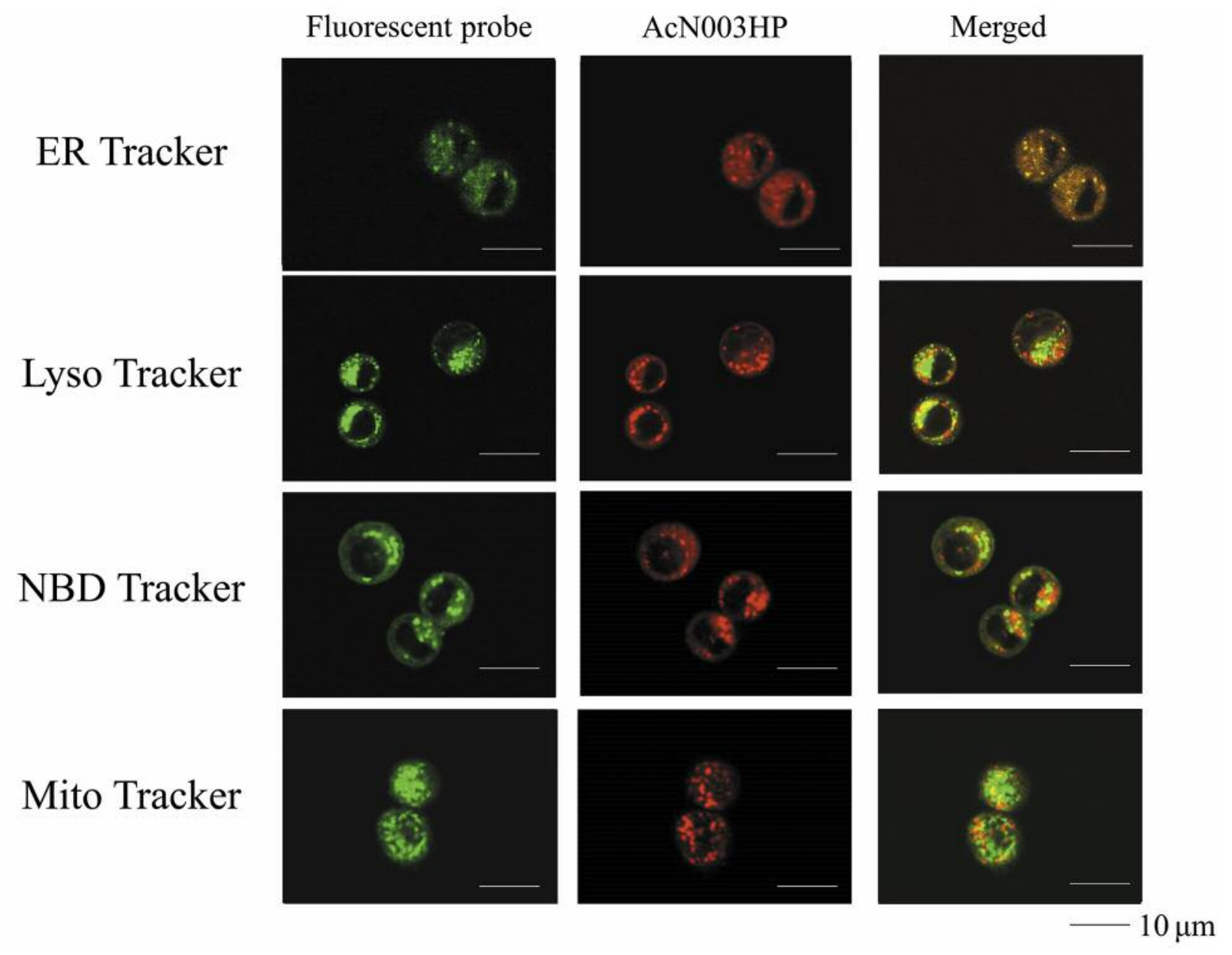

Figure 3. Subcellular localization of AcN003HP. MKN45 cells were loaded with AcN003HP for 24 h and labeled with Mito Tracker Green, Lyso Tracker Green, NBD C6 ceramide Green, or ER Tracker Green. The images were obtained by confocal microscopy (original magnification, x300; scale bar, $10 \mu \mathrm{m})$.

\section{Results}

PDT with AcN003HP showed a very strong antitumor effect for esophageal, gastric and colon cancer cells in vitro. To determine the $\mathrm{IC}_{50}$ at $24 \mathrm{~h}$ after irradiation, a WST assay was performed. As shown in Table I, PDT using AcN003HP induced 13,000 to 36,000 times more cell death than TS. This result shows that PDT using AcN003HP exerts an antitumor effect similar to G-chlorin e6 (15).

The uptake of AcN003HP or TS in cancer cells was compared using MKN45 and HT29 cells in vitro. Uptake was estimated by flow cytometry analysis. As shown in Figure 2, the uptake of AcN003HP was 100-200 times higher than TS.

The subcellular localization of AcN003HP was investigated using confocal microscopy and intracellular organelle-specific fluorescence probes. AcN003HP localized with ER Tracker Green, indicating that AcN003HP mainly accumulates in the endoplasmic reticulum (Figure 3).

SOSG reagent was used to detect singlet oxygen production from PDT using AcN003HP or TS. PDT using AcN003HP produced more singlet oxygen than PDT using TS (Figure 4). The relative fluorescence intensity ratios of the PSs in tumors and normal tissue adjacent to the tumor were measured using a spectrometer to examine the accumulation of PSs in tumor cells over time. The relative fluorescence intensity ratio of G-chlorin e6 was highest at $30 \mathrm{~min}$, while that of AcN003HP was highest at 90 min (Figure 5).

To examine the antitumor effect of AcN003HP PDT in vivo, PDT using mice xenograft tumor models was performed. MKN45 cancer cells were implanted subcutaneously and 10 days later, AcN003HP or TS was administered to the mice via the tail vein at a dose of $1.56 \mu \mathrm{mol} / \mathrm{kg}$. After $90 \mathrm{~min}$, tumors were irradiated with 664-nm LASER at $100 \mathrm{~J} / \mathrm{cm}^{2}$. AcN003HP 


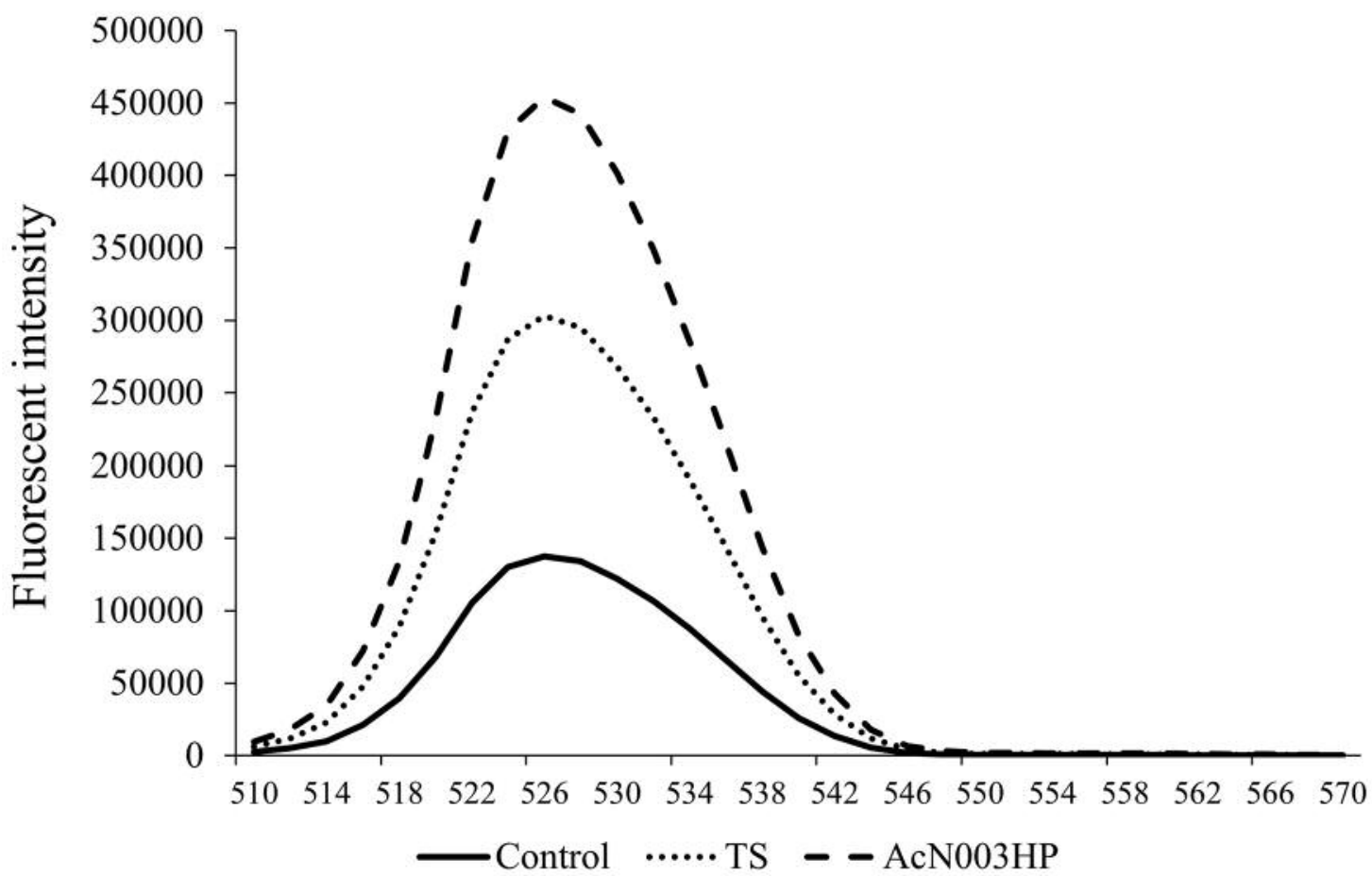

Figure 4. Production of singlet oxygen, measured by Singlet Oxygen Sensor Green (SOSG) reagent. MKN45 cells were incubated with $1 \mu M$ photosensitizer in culture medium for $24 \mathrm{~h}$, then SOSG reagent was added and the cells were irradiated with $16 \mathrm{~J} / \mathrm{cm}^{2} \mathrm{of} 660$-nm light-emitting diode light, and assessed for reagent accumulation using a fluorescence microplate reader. Data are means \pm standard error of eight independent experiments.

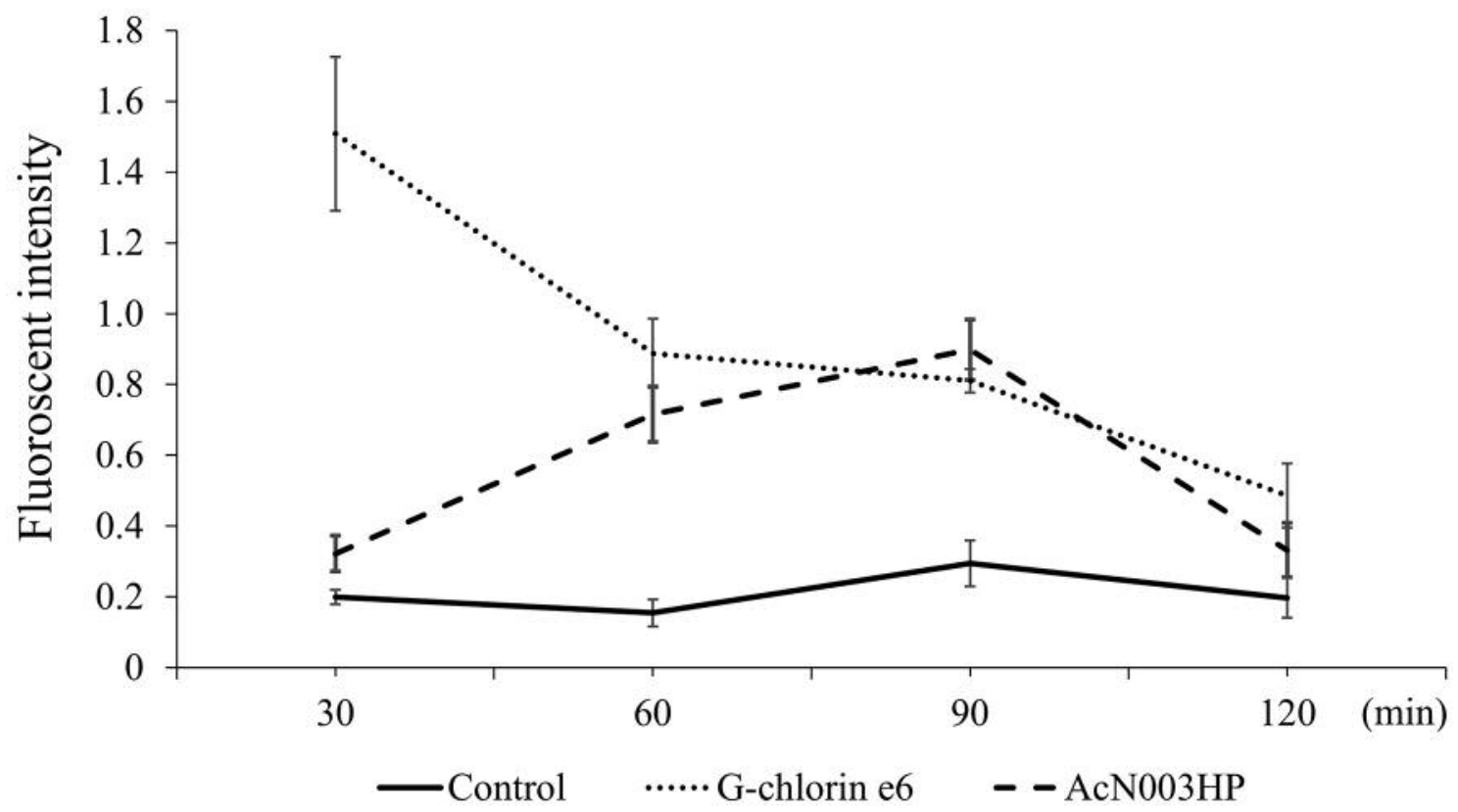

Figure 5. Accumulation of photosensitizers (PSs) in tumor cells. Each PS was administered via the tail vein to mice with implanted tumors, and the $P S$ fluorescence in the tumors was measured every $30 \mathrm{~min}$ for $120 \mathrm{~min}$ using a spectrometer. The relative intensities of the PSs measured by the spectrometer were observed to have a linear correlation with PS concentration. Data are shown as means \pm standard error ( $n=10$ per group). 


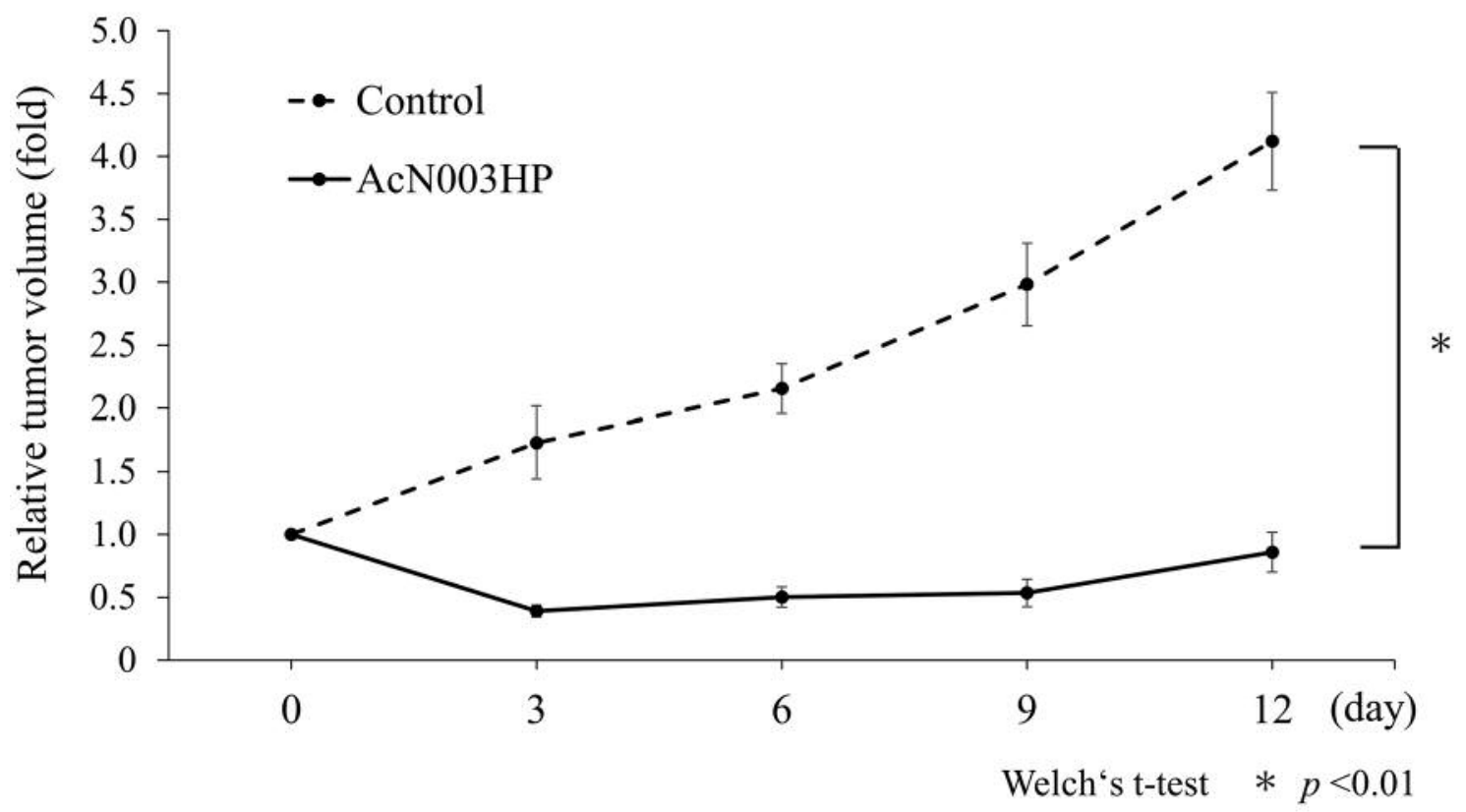

Figure 6. Antitumor effects of photodynamic therapy (PDT) in a xenograft mouse model. Mice were irradiated at $100 \mathrm{~J} / \mathrm{cm}^{2}$ using a diode laser at $664 \mathrm{~nm}, 90$ min after injection of the photosensitizer. PDT was performed on day 0 and tumor volumes were monitored for 12 days in total. Data are shown as means \pm standard error ( $n=7$ each, for control, talaporfin sodium, and AcN003HP). Data for talaporfin sodium PDT are not shown as no mice survived longer than 3 days. *Significant difference between groups, $p<0.01$, Welch's $t$ test.

exerted strong tumor suppressing effect compared to control and adverse events were not observed (Figure 6). Also, tumor was completely disappeared in 2 out of 7 mice (CR rate, $28.5 \%$ ). Three days after irradiation all mice of the TS PDT group died.

\section{Discussion}

AcN003HP, a chlorin-based, glucose-conjugated PS, was developed to overcome the problems of PDT using the previously developed glucose-conjugated PS, such as cellular uptake, chlorin-dependent photocytotoxicity, appropriate speed of accumulation, ROS production, and PS excretion. TS, a second-generation PS for PDT, is superior to the firstgeneration PS, porfimer sodium, in terms of its antitumor effect and excretion from the body. However, the antitumor effect of PDT and the tumor selectivity by PSs are still not sufficient. Therefore, a next-generation PS, G-chlorin e6, was developed, which is a glucose-conjugated chlorin that uses the Warburg effect, whereby cancer cells in general consume more glucose than normal cells (15).

While PDT using G-chlorin e6 has a very strong antitumor effect, G-chlorin e6 is rapidly cleared from the body. Because of this rapid excretion, there is a possibility that Gchlorin e6 does not sufficiently accumulate in the tumor cells within the limited time available. Moreover, the amount of ROS that G-chlorin e6 can generate has not been confirmed.
In order to delay the excretion of G-chlorin e6, acetyl groups were attached to G-chlorin e6 and produced the newly synthesized AcN003HP. Acetyl groups act as a protecting group, especially for the hydroxyl group and vary in biological activity. A previous study reported that acetylated compounds are cleared from the body more slowly than compounds with other protecting groups (19). Our current results indicated the excretion of AcN003HP from the mouse took $90 \mathrm{~min}$, while that of G-chlorin e6 took $30 \mathrm{~min}$. Thus, the addition of acetyl groups to G-chlorin e6 extended the excretion time of AcN003HP. The antitumor effects of PDT using AcN003HP were also very strong, and almost the same as that of G-chlorin e6 in vivo and in vitro $(13,15)$.

The mechanism which allows a PS to accumulate in intracellular organelles is of great interest to the biomedical research community. It is widely accepted that nano-sized compounds penetrate into cells by endocytic processes (20). Studies have been conducted to determine the cellular uptake pathways for PSs, such as clathrin-mediated endocytosis and macropinocytosis $(21,22)$. But it is not completely clear how the cells take up PSs with endocytosis. So, further investigation into the mechanism of PSs accumulation in tumor cells is required.

In the past decades, the molecular effectors of cell death pathways induced by PDT have been revealed. PDT uses the PS localized within intracellular organelles of tumor cells such as endoplasmic reticulum, mitochondria, Golgi bodies 
and lysosomes, to achieve its effect. PSs localized in tumor cells, absorb visible light, leading to the generation of highly cytotoxic ROS, mainly singlet oxygen. This photochemical reaction induces apoptotic and autophagic pathways $(23,24)$.

In the present study, the cellular uptake and subcellular localization of AcN003HP was investigated using confocal microscopy. AcN003HP was found to accumulate mainly in the endoplasmic reticulum. PDT using AcN003HP produced a greater amount of singlet oxygen than PDT using TS.

Our in vitro investigation of the antitumor effect showed that AcN003HP caused 13,000 to 36,000 times more cell death than TS. In xenograft tumor models, PDT using AcN003HP suppressed tumor growth and had no adverse effects on the surrounding tissues, compared to light alone or TS PDT. Some studies have confirmed the relationship between photodamaged endoplasmic reticulum and cell death pathways $(25,26)$. Light activation of a PS localized to endoplasmic reticula causes oxidative damage to the $\mathrm{Ca}^{2+}$ homeostasis pathways in the endoplasmic reticulum, which initiates apoptotic and autophagic pathways (26-28).

Given the above, AcN003HP PDT would induce cell death via necrosis and/or autophagy by increasing the production of ROS, inducing oxidative stress in the endoplasmic reticulum, and triggering cell death pathways. Therefore, PDT using AcN003HP is likely to have a strong antitumor effect.

In conclusion, we consider that AcN003HP might be the best glucose-conjugated chlorin synthesized so far because of its strong antitumor PDT effect, appropriate excretion time, and production of high amounts of ROS.

\section{Conflicts of Interest}

The Authors have declared that no conflict of interest exists regarding this study.

\section{Authors' Contributions}

Conception and design: H. Ichikawa, H. Nishie, M. Tanaka, A.Kato, H Kataoka; Development of methodology: H. Ichikawa, H. Nishie, M.Tanaka, A. Kato, S. Yano, H. Yamaguchi, A. Nomoto. H. Kataoka; Acquisition of data (provided animals, acquired and managed patients, provided facilities, etc.): H.Ichikawa, H. Nishie, M. Tanaka, A. Kato, H. Kataoka; Analysis and interpretation of data (e.g., statistical analysis, biostatistics, computational analysis): H.Ichikawa, H. Nishie, E.Kubota, H. Kataoka; Writing, review, and/or revision of the manuscript: H.Ichikawa, H. Nishie, T, M. Tanaka, H. Kataoka; Administrative, technical, or material support (i.e., reporting or organizing data, constructing databases): T. Mizoshita, S.Shimura, S. Tanida; Study supervision: T. Mizoshita, S. Shimura, S. Tanida, H. Kataoka; Other (synthesis of PDT photosensitizer): S. Yano, H. Yamaguchi, A. Nomoto.

\section{Acknowledgments}

Funding: This work was partially supported by JSPS KAKENHI (2017-2019) grant number 17K09356 (to H. Kataoka); JSPS
KAKENHI (2018-2020) grant number 18K05161 (to S. Yano); JSPS KAKENHI (2019-2022) grant number 19H02791 (to A. Nomoto); JSPS KAKENHI (2017-2019) grant number 18K08013 (to $\mathrm{M}$. Tanaka); The Japanese Foundation for Research and Promotion of Endoscopy Grant (2018) (to M. Tanaka); Kobayashi Foundation for Cancer Research (2018-2019) (to M. Tanaka); Takeda Science Foundation (2018-2019) (to M. Tanaka); The Nitto Foundation (2019) (to M. Tanaka); JSPS KAKENHI (2018-2020) grant number 18 K15758 (to H. Nishie); the Translational Research Network Program of the Japan Agency for Medical Research and Development; and AMED ACT-MS (2018-2019) grant number JUTAK23050.

\section{References}

1 Dolmans DE, Fukumura D and Jain RK: Photodynamic therapy for cancer. Nat Rev Cancer 3(5): 380-387, 2003. PMID: 12724736. DOI: $10.1038 / \mathrm{nrc} 1071$

2 Dougherty TJ, Gomer CJ, Henderson BW, Jori G, Kessel D, Korbelik M, Moan J and Peng Q: Photodynamic therapy. J Natl Cancer Inst 90(12): 889-905, 1998. PMID: 9637138. DOI: 10.1093/jnci/90.12.889

3 Yano S, Hirohara S, Obata M, Hagiya Y, Ogura SI, Ikeda A, Kataoka H, Tanaka M and Joh T: Current states and future views in photodynamic therapy. J Photochem Photobiol 12(1): 46-67, 2011. DOI: 10.1016/j.jphotochemrev.2011.06.001

4 Castano AP, Demidova TN and Hamblin MR: Mechanisms in photodynamic therapy: Part one - photosensitizers, photochemistry and cellular localization. Photodiagnosis Photodyn Ther 1(4): 279-293, 2004. PMID: 25048432. DOI: 10.1016/S1572-1000(05)00007-4

5 Huang Z: A review of progress in clinical photodynamic therapy. Technol Cancer Res Treat 4(3): 283-293, 2005. PMID: 25048432. DOI: $10.1177 / 153303460500400308$

6 Castano AP, Demidova TN and Hamblin MR: Mechanisms in photodynamic therapy: Part two - cellular signaling, cell metabolism and modes of cell death. Photodiagnosis Photodyn Ther 2(1): 1-23, 2005. PMID: 25048553. DOI: 10.1016/S15721000(05)00030-X

7 Juarranz A, Jaen P, Sanz-Rodriguez F, Cuevas J and Gonzalez S: Photodynamic therapy of cancer. Basic principles and applications. Clin Transl Oncol 10(3): 148-154, 2008. PMID: 18321817. DOI: 10.1007/s12094-008-0172-2

8 Brown SB, Brown EA and Walker I: The present and future role of photodynamic therapy in cancer treatment. Lancet Oncol 5(8): 497-508, 2004. PMID: 15288239. DOI: 10.1016/S14702045(04)01529-3

9 Muragaki Y, Akimoto J, Maruyama T, Iseki H, Ikuta S, Nitta M, Maebayashi K, Saito T, Okada Y, Kaneko S, Matsumura A, Kuroiwa T, Karasawa K, Nakazato $\mathrm{Y}$ and Kayama T: Phase ii clinical study on intraoperative photodynamic therapy with talaporfin sodium and semiconductor laser in patients with malignant brain tumors. J Neurosurg 119(4): 845-852, 2013. PMID: 23952800. DOI: 10.3171/2013.7.JNS13415

10 Kato H, Furukawa K, Sato M, Okunaka T, Kusunoki Y, Kawahara M, Fukuoka M, Miyazawa T, Yana T, Matsui K, Shiraishi $\mathrm{T}$ and Horinouchi $\mathrm{H}$ : Phase II clinical study of photodynamic therapy using mono-l-aspartyl chlorin e6 and diode laser for early superficial squamous cell carcinoma of the lung. Lung Cancer 42(1): 103-111, 2003. PMID: 14512194. DOI: $10.1016 / \mathrm{S} 0169-5002(03) 00242-3$ 
11 Tanaka M, Kataoka H, Yano S, Ohi H, Moriwaki K, Akashi H, Taguchi T, Hayashi N, Hamano S, Mori Y, Kubota E, Tanida S and Joh T: Antitumor effects in gastrointestinal stromal tumors using photodynamic therapy with a novel glucose-conjugated chlorin. Mol Cancer Ther 13(4): 767-775, 2014. PMID: 24552 777. DOI: 10.1158/1535-7163.MCT-13-0393

12 Tanaka M, Kataoka H, Yano S, Sawada T, Akashi H, Inoue M, Suzuki S, Inagaki Y, Hayashi N, Nishie H, Shimura T, Mizoshita T, Mori Y, Kubota E, Tanida S, Takahashi S and Joh T: Immunogenic cell death due to a new photodynamic therapy (pdt) with glycoconjugated chlorin (g-chlorin). Oncotarget 7(30): 4724247251, 2016. PMID: 27363018. DOI: 10.18632/ oncotarget.9725

13 Hayashi N, Kataoka H, Yano S, Tanaka M, Moriwaki K, Akashi H, Suzuki S, Mori Y, Kubota E, Tanida S, Takahashi S and Joh T: A novel photodynamic therapy targeting cancer cells and tumorassociated macrophages. Mol Cancer Ther 14(2): 452-460, 2015. PMID: 25512617. DOI: 10.1158/1535-7163.MCT-14-0348

14 Kataoka H, Nishie H, Hayashi N, Tanaka M, Nomoto A, Yano $\mathrm{S}$ and Joh T: New photodynamic therapy with next-generation photosensitizers. Ann Transl Med 5(8), 2017. PMID: 28616398. DOI: $10.21037 / \mathrm{atm} .2017 .03 .59$

15 Nishie H, Kataoka H, Yano S, Yamaguchi H, Nomoto A, Tanaka M, Kato A, Shimura T, Mizoshita T, Kubota E, Tanida S and Joh T: Excellent antitumor effects for gastrointestinal cancers using photodynamic therapy with a novel glucose conjugated chlorin e6. Biochem Biophys Res Commun 496(4): 1204-1209, 2018. PMID: 29408755. DOI: 10.1016/j.bbrc.2018.01.171

16 Jung K, Schulze $G$ and Reinholdt C: Different diuresisdependent excretions of urinary enzymes: N-acetyl-beta-dglucosaminidase, alanine aminopeptidase, alkaline phosphatase, and gamma-glutamyltransferase. Clin Chem 32(3): 529-532, 1986. PMID: 2868815. DOI: None

17 Hatori A, Shigematsu A and Tsuya A: The metabolism of aspirin in rats; localization, absorption, distribution and excretion. Eur J Drug Metab Pharmacokinet 9(3): 205-214, 1984. PMID: 6519122. DOI: $10.1007 / \mathrm{BF} 03189643$

18 Nishie H, Kataoka H, Yano S, Kikuchi JI, Hayashi N, Narumi A, Nomoto A, Kubota E and Joh T: A next-generation bifunctional photosensitizer with improved water-solubility for photodynamic therapy and diagnosis. Oncotarget 7(45): 74259-74268, 2016. PMID: 27708235. DOI: 10.18632/oncotarget. 12366

19 Nogami H, Hanano M, Awazu S and Imaoka K: A pharmacokinetic study on the metabolism and excretion of sulpyrin in the rats (Author's translation). Yakugaku Zasshi 93(12): 1585-1592, 1973. PMID: 4361309. DOI: 10.1248/yakushi1947.93.12_1585

20 Soriano J, Stockert JC, Villanueva A and Canete M: Cell uptake of $\mathrm{zn}$ (ii)-phthalocyanine-containing liposomes by clathrinmediated endocytosis. Histochem Cell Biol 133(4): 449-454, 2010. PMID: 20191285. DOI: 10.1007/s00418-010-0679-9
21 Rejman J, Bragonzi A and Conese M: Role of clathrin- and caveolae-mediated endocytosis in gene transfer mediated by lipo- and polyplexes. Mol Ther 12(3): 468-474, 2005. PMID: 15963763. DOI: $10.1016 /$ j.ymthe 2005.03 .038

22 Rejman J, Conese M and Hoekstra D: Gene transfer by means of lipo- and polyplexes: Role of clathrin and caveolae-mediated endocytosis. J Liposome Res 16(3): 237-247, 2006. PMID: 16952878. DOI: $10.1080 / 08982100600848819$

23 Buytaert E, Dewaele M and Agostinis P: Molecular effectors of multiple cell death pathways initiated by photodynamic therapy. Biochim Biophys Acta 1776(1): 86-107, 2007. PMID: 17693025. DOI: 10.1016/j.bbcan.2007.07.001

24 Kessel D, Vicente MG and Reiners JJ Jr.: Initiation of apoptosis and autophagy by photodynamic therapy. Autophagy 2(4): 289290, 2006. PMID: 16921269. DOI: 10.4161/auto.2792

25 Marchal S, François A, Dumas D, Guillemin F and Bezdetnaya L: Relationship between subcellular localisation of foscan ${ }^{\circledR}$ and caspase activation in photosensitised mcf-7 cells. Br J Cancer 96: 944, 2007. PMID: 17325708. DOI: 10.1038/sj.bjc.6603631

26 Buytaert E, Callewaert G, Hendrickx N, Scorrano L, Hartmann D, Missiaen L, Vandenheede JR, Heirman I, Grooten J and Agostinis P: Role of endoplasmic reticulum depletion and multidomain proapoptotic bax and bak proteins in shaping cell death after hypericin-mediated photodynamic therapy. FASEB J 20(6): 756758, 2006. PMID: 16455754. DOI: 10.1096/fj.05-4305fje

27 Ogata M, Hino S, Saito A, Morikawa K, Kondo S, Kanemoto S, Murakami T, Taniguchi M, Tanii I, Yoshinaga K, Shiosaka S, Hammarback JA, Urano F and Imaizumi K: Autophagy is activated for cell survival after endoplasmic reticulum stress. Mol Cell Biol 26(24): 9220-9231, 2006. PMID: 17030611. DOI: 10.1128/MCB.01453-06

28 Kouroku Y, Fujita E, Tanida I, Ueno T, Isoai A, Kumagai H, Ogawa S, Kaufman RJ, Kominami E and Momoi T: Er stress (perk/eif2alpha phosphorylation) mediates the polyglutamineinduced 1c3 conversion, an essential step for autophagy formation. Cell Death Differ 14(2): 230-239, 2007. PMID: 16794605. DOI: $10.1038 /$ sj.cdd.4401984 